\title{
Human Papilloma Virus and Anal Cancer
}

\author{
João Batista de Sousa and Leonardo de Castro Durães \\ University of Brasilia \\ Brazil
}

\section{Introduction}

Anal cancer is a rare tumor, whose incidence has increased in recent years. Its incidence is approximately 1.5 / 100,000 in the general population (Jemal et al, 2009, Siegel et al, 2011). Historically anal cancer is more common in women, however the incidence in men has been increasing, especially among those who practice anal sex with men (MSM).

Among the risk factors are human papillomavirus (HPV), smoking, immunosuppression and anal sex (Uronis et al, 2007)

The most common anal cancer is the squamous cell carcinoma. It may be keratinized or nonkeratinized. Adenocarcinoma may occur, however, it resembles the lower rectal cancer and should follow its principles of treatment. (Nivatvongs, 2006) According to the World Health Organization (WHO), approximately $80 \%$ of tumors of the anal canal are squamous cell type and these are divided in squamous cell carcinoma tumors, basaloid (cloacogenic) and mucoepidermoid. In this classification of tumors of the anal region, WHO considers the anal verge, anal canal, the anal transition zone and the rectal type mucosae of the anal canal. Therefore, other histological types of tumors can arise in the anal canal. Adenocarcinomas may originate in the rectal type mucosae in the anal canal and in the path of a long evolution anal fistula or in the epithelium of the anal glands. Other tumors may be lymphoma, melanoma, Kaposi's sarcoma, Bowen's disease and Paget's disease. (Table 1)

\begin{tabular}{|l|l|}
\hline HISTOLOGICAL TYPE & ORIGIN \\
\hline SQUAMOUS CELL CARCINOMA & SKIN AND ANAL VERGE \\
\hline \multirow{2}{*}{ ADENOCARCINOMA } & RECTAL TYPE MUCOSAE \\
& $\begin{array}{l}\text { ANAL GLANDS } \\
\text { FISTULA'S PATH }\end{array}$ \\
\hline LYMPHOMAS & ANAL CANAL \\
\hline \multirow{2}{*}{ MELANOMA } & $\begin{array}{l}\text { ANAL CANAL } \\
\text { ANAL VERGE }\end{array}$ \\
\hline KAPOSI & ANAL CANAL \\
& ANAL VERGE \\
\hline BOWEN & ANAL VERGE \\
\hline PAGET & ANAL VERGE \\
\hline
\end{tabular}

Table 1. Histological types of malignant tumors of the anal canal and its origin in the anorectal region. 
The human papilloma virus (HPV) belongs to Papillomavirus genus of the family Papillomaviridae. It causes the lesion called condyloma acuminata (from the greek "Kondilus", that means rounded tumor, and the latin "acuminare" meaning make sharp). Infection by HPV is a sexually transmitted viral disease most common in sexually active population. According to the Centers for Disease Control and Prevention (CDC) between 1966 and 1981 there was a 500\% increase in the incidence of condyloma acuminata. In 1996 it was estimated that the incidence per year was 500 thousand to 1 million new cases and 25\% of the population was infected. Therefore, the Human Papilloma Virus (HPV) is the most common sexually transmitted disease. Its association with cervical cancer is well established. However, their role in anal cancer as the primary cause, not just as a cofactor, is being increasingly accepted. There are several serotypes of HPV, with different risks of inducing cancer.

\section{Anatomy of the anal canal}

The anal canal is a small area that extends from the anal verge to the rectal mucosa, bypassing the dentate line. It is a complex area that has different histological features. The diversity of cells in this region is wide for being the junction of embryonic layers. According to World Health Organization (WHO), the anal canal is defined as the terminal part of the large intestine, beginning at the upper surface of the anorectal ring and passing through the pelvic floor at the anus. The lower part extends from the dentate line and downwards to the anal verge. This was therefore the surgical anal canal. The lateral limit is 5 to $6 \mathrm{~cm}$ from anal verge. (Nivatvongs, 2006). The skin of the anal margin consists of a keratinized squamous epithelium and eccrine and apocrine glands and other appendages such as hair follicles and may thus be compromised for any condition that affects the skin itself and its structures such as malignant tumors.

Lymphatic drainage above the dentate line is for the lymphatic chain of the lower mesenteric vessels passing trough the lymphatic chain of the superior rectal vessels. Lymphatic drainage below the dentate line runs to the inguinal lymph nodes.

The anal canal represents the end of the squamous mucosa and the beginning of a transition zone for non-squamous mucosa. There is a transition from squamous epithelium to an immature epithelium, in which a squamous epithelium overlaps a columnar epithelium, to a squamous metaplastic area of tissue that occurs above the dentate line, which has a columnar epithelium.

Therefore tumors of this region may be keratinized or non-keratinized, but with similar biology and prognosis.

\section{Human Papilloma Virus (HPV)}

HPV is a sexually transmitted disease of high incidence. HPV is a DNA Papilloma virus with an 8-kilobase genome. Systematic reviews of the literature showed a prevalence of genital HPV infection ranging from $1.3 \%$ to $72.9 \%$. These variations are due to different study populations and different diagnostic methods. (Dietz et al. 2011, Uronis et al. 2007, Bean et al. 2009, Chin Hong et al. 2004, Darragh et al. 2011, Fox 2006, Giuliano et al. 2010) 
In most patients, the virus is rapidly recognized by the immune system, with only $1 \%$ of patients developing clinical symptoms of infection (anal warts). The estimated prevalence of subclinical infection varies between 10 and 46\% (Welton et al. 2004)

Transmission of the virus is not entirely preventable by using condoms and sexual abstinence is the only way to effective prevention. The virus can remain in the secretion at the base of the penis and scrotum, making the condoms ineffective.

Chronic infection occurs in a minority of patients who are exposed to HPV. For this to occur the virus must gain access to the basal and parabasal cells of the anorectal transition zone through erosion or disruption of normal mucosal barrier, which can occur in anal sex, anorectal trauma from other causes, or concomitant presence of infections of other sexually transmitted diseases. There are more than 80 different subtypes of HPV. Among them, at least 23 have potential for infection of the anogenital mucosa. Each subtype has a different potential to induce malignancy. HPV 6 and 11 serotypes are most associated with genital warts and have less oncogenic potential. Already serotypes 16,18,31, 33, 35, 39, 45, 50, 51, 53, 56, 58, 59 and 68 are most commonly identified in high-grade dysplasia or carcinoma (Uronis et al, 2007). The serotype can be evidenced by specific test for DNA. Serotype 16 is the most prevalent and associated with $70 \%$ of cases of anal cancer.

Anal warts are a benign condition not associated with mortality. However, it is a disease that causes psychosocial stress, shame and embarrassment. The incubation period is 3 weeks to 8 months; most of them develop 2-3 months after infection with HPV. Over $90 \%$ of warts are caused by serotypes 6 and 11, however approximately one third achieve co-infection with oncogenic serotypes.

Several cancers are attributed to HPV infection. These include cancers of the cervix, vagina, vulva, penis, oral cavity, head and neck and anal canal. The two most common HPVassociated cancers are anal cancer and cervical cancer. Both occur in the mucous epithelium, while anal cancer also occurs in the perianal keratinized epithelium.

Several epidemiological studies have assessed the association between HPV and anal CA. In a recent study, DURAES and SOUSA showed a strong correlation between CA and anal HPV in Brazil. (Duraes \& Sousa, 2010)

Anal sex is the major risk factor for HPV infection, but heterosexual men who did not have sex with men may present with HPV infection.

The prevalence of HPV infection in men who have sex with men (MSM) HIV negative reaches 57\% (Chin-Hong et al, 2004)

\section{Anal cancer}

Anal cancer accounts for approximately $2.6 \%$ of carcinomas of the large intestine. Its incidence is increasing in the United States, Europe and South America. The American incidence has been increasing over the past 40 years. In 2003, there was an estimated 4,000 new cases in the United States. In 2007, about 4650 new cases, and in 2009 the number was estimated to be 5,290 new cases (2100 men and 3190 women). In 2011 the figure was 5820 new cases (2140 men and 3680 women) (Siegel et al, 2011). 
The incidence rate is higher in women in all age groups, however the incidence in men has increased. The incidence rates are 1.4 per 100,000 in men and 1.7 per 100,000 in women.

Anal cancer was initially associated with chronic inflammatory conditions such as Crohn's disease. Then viral genital infections were associated. HPV infection, with or without immune compromise was seen as the main risk factor for the development of anal dysplasia, which is the precursor lesion of anal cancer.

Other associated risk factors are anal sex, number of sexual partners, smoking and history of anal warts. For women the history of vulvar intraepithelial neoplasia and high-grade cervical or vulvar cancer are considered risk factors. Imunossupressed post-transplant patients are also considered high risk.

The populations most at risk for anal cancer are men who have sex with men (MSM), regardless of HIV infection. Other risk groups are imunossupressed individuals and HIV positive.

Although it is a rare cancer, the incidence in men who have sex with men (MSM) HIVpositive has been increasing, especially in those using antiretroviral therapies. The incidence of anal cancer in HIV-negative MSM is approximately 35 per 100000. In the HIV-positive MSM the incidence range from 42 to 137 per 100,000 per year.

Symptoms include rectal bleeding (in half of patients), pain, and rectal mass sensation. $20 \%$ of patients have no symptoms. Cancer of the anal canal extends to the rectum or perianal skin in half of the cases.

Anal cancer can give metastases via the lymphatic system, and less frequently, can be hematogenous. Anal cancer below the dentate line is at risk of metastasis to the inguinal and femoral nodes. Above the dentate line the risk of metastasis is to the perirectal lymph nodes.

The diagnosis in early stage is possible by clinical evaluation by detecting the presence of a papular nodule or tumor in the anal canal, of varying size and hardness, which may be fixed or not the muscle planes. You can often see a fissure at the anal inspection, presenting itself as an ulcerated lesion with raised borders and irregular, hard, lumpy, very painful that easily bleeds when touched. Proctological examination for evaluation and biopsy is often only possible with the anesthetized patient. In advanced disease, vegetative ulcers lesions are often observed, advancing extensively to the perineum, vulva, vagina and sacrococigeal region. These advanced lesions can cause pain to urinate, evacuate or even walk. The not diagnosed, untreated disease evolves compromising the anal sphincter apparatus and leads to progressive stenosis of the anal canal and can result in fecal incontinence and production of foul-smelling discharge. The differential diagnosis should be done with various anorectal diseases, and the anal fissure disease that requires further attention. The typical pain of the fissure that occurs after the evacuation can also occur in early carcinoma, but with the progression of the disease the pain becomes continuous, persistent and almost unbearable. The atypical location, outside the median line and above the dentate line is important data to rule out idiopathic anal fissure.

\section{Anal cancer staging}

The staging for anal cancer is done through the TNM system (tumor, node, metastasis). The TNM is based on the anatomical extent, where T refers to the primary tumor, $\mathrm{N}$ refers to lymph node metastases, and $\mathrm{M}$ refers to the presence or absence of distant metastases. 
As for the T rating:

Tis or carcinoma in situ.

T1: Tumor measures $2 \mathrm{~cm}$ or less.

T2: Tumor is between 2 and $5 \mathrm{~cm}$.

T3: Tumor is larger than $5 \mathrm{~cm}$.

T4: Tumor of any size invading adjacent structures such as the urethra, vagina or bladder.

Regarding the classification $\mathrm{N}$ :

N0: No lymph node metastases

N1: Metastasis in perirectal lymph nodes

N2: Unilateral metastasis in inguinal lymph nodes or unilateral internal iliac nodes

N3: Bilateral metastasis in inguinal lymph nodes or bilateral internal iliac

As for the $\mathrm{M}$ rating:

M0: No distant metastases.

M1: Distant metastases.

\section{Staging}

The staging of anal carcinoma requires a digital rectal exam, a CT scan of chest, abdomen and pelvis. In any suspicion of affected lymph nodes, fine needle aspiration biopsy should be performed. The use of PET CT is not well established.

\begin{tabular}{|l|l|l|l|}
\hline Stage & T & N & M \\
\hline Stage 0 & Tis & N0 & M0 \\
\hline Stage I & T1 & N0 & M0 \\
\hline Stage II & T2 & N0 & M0 \\
\hline Stage II & T3 & N0 & M0 \\
\hline Stage III A & T1, T2, T3 & N1 & M0 \\
\hline Stage III A & T4 & N1 & M0 \\
\hline Stage III B & T4 & N1 & M0 \\
\hline Stage III B & Any T & N2, N3 & M0 \\
\hline Stage IV & Any T & Any N & M1 \\
\hline
\end{tabular}

Table 2. TNM Staging for Anal Cancer.

The gynecological examination, including cervical cancer screening is recommended for women with anal cancer. The HIV test is recommended. In case of positivity, CD4 levels should be evaluated.

The endoanal ultrasound, especially with three-dimensional view, helps in assessing the depth of tumor invasion and involvement of adjacent nodes. 


\section{Natural history of high grade squamous intraepithelial lesions and anal cancer}

Much of the information about anal cancer, because of its low incidence, is extrapolated from cervical cancer. This extrapolation is due to the great similarity between the histology and histopathology of the tissues involved.

HPV can lead to formation of anal warts, low-grade squamous intraepithelial lesion (LSIL), high-grade squamous intraepithelial lesion (HSIL) and cancer. The mechanisms of progression of lesions in the anal canal are not fully elucidated. (Ortoski \& Kell, 2011)

The development of squamous cell carcinoma of the anus appears to be similar to squamous cell carcinoma of the cervix, which means, transition from anal low-grade squamous intraepithelial lesions (LSIL) for anal high-grade squamous intraepithelial lesions (HSIL) and then to squamous cell carcinoma.

Genital warts are typically caused by serotypes of HPV that are at low risk for induction of carcinoma. LSIL can be identified in association with warts, especially those flat lesions. The presence of concomitant condylomatous lesions and HSIL is uncommon in immunocompetent patients. However, in immunocompromised patients, HSIL is usually found in association with genital warts. These patients have infections with multiple HPV types, compared with immunocompetent patients, which may explain this finding.

Both the cervix and the anal canal have regions of metaplasia replacing glandular epithelium with squamous epithelium. HPV infects the basal cells causing an interruption in the cycle of cell differentiation and maturation of precursors leading to the development of cancer.

The virus interferes with the mechanisms of the cell cycle, resulting in cell proliferation during latency. There is a loss of cell cycle inhibition through the action of two viral genes E6 and E7. The E7 interferes with the cell cycle, allowing the cell to progress from G1 to S phase. The events caused by E7 are not sufficient for malignant transformation. Accumulated genetic errors in cell replication are necessary for malignant transformation, which is consistent with the fact that chronic infection with HPV is necessary for the onset of cancer. The accumulation of genetic errors is facilitated by E6. This protein binds to p53, leading to degradation it. The p53 protein is a protein important for regulating the cell cycle that leads to apoptosis of cells with accumulated genetic errors, preventing replication errors.

Taking into account the high incidence of HSIL in HIV-positive MSM, it appears that only a minority will progress to cancer, but it is not possible to predict which lesions will progress, regress or persist.

The prevalence of high-grade squamous intraepithelial lesions (HSIL) confirmed by biopsy is very high: approximately $50 \%$ of homosexual HIV positive and $25 \%$ of HIV negative MSM.

High-grade anal dysplasia in HIV-positive men can progress to invasive cancer within a short period of time (Kreuter et al, 2010) 
The role of HIV infection in anal cancer has not been elucidated. Population studies failed to show a correlation, including a study by the authors of epidemiological data in Brazil. The use of antiretroviral therapy and increased survival of HIV-positive can change this data in the future.

\section{Histopathology of intraepithelial lesions and anal cancer}

The classification follows the same cytological classification of cervical cytology:

ASCUS: Atypical Squamous Cells Undetermined Significance

ASCH: Atypical Squamous Cells suspicious for HSIL

ASIL: Atypical Squamous intraepithelial Lesion

LSIL: Low-grade Squamous intraepithelial Lesion

HSIL: High-grade Squamous intraepithelial Lesion

SCC: Squamous Cell Carcinoma

Histological classification terminology follows below:

AIN: Anal intraepithelial neoplasia

AIN 1: Mild dysplasia

AIN 2: Moderate dysplasia

AIN 3: Severe dysplasia / carcinoma in situ

Invasive Anal Carcinoma

The LSIL corresponds to an AIN. The HSIL corresponds to AIN2, carcinoma in situ or AIN3. The ASCUS and ASCH don't have all the features of HSIL, but are not classified as benign.

Anal cancer is classified by degree of differentiation and histogenesis.

There are several microscopic appearances, including large-cell keratinizing, large-cell and basaloid nonkeratinizing. The term cloacogênic carcinoma is used to basaloid tumors and forms of non-keratinized squamous cell carcinoma.

Although squamous intraepithelial lesions and squamous cell carcinoma lesions are most often found, the distinction between squamous cell carcinoma poorly differentiated and other lesions such as lymphoma and melanoma can be difficult, sometimes requiring use of immunohistochemistry.

\section{Screening}

The screening performed in cervical cancer led to a decrease in the incidence of cancer with early detection of pre malignant lesions. Taking into account the similarity between anal cancer and cervical cancer, there are proposals for population screening for anal cancer. (Darragh \& Winkler, 2011) 
The goal of screening is to identify and treat cancer and early high grade squamous intraepithelial lesion (HSIL). As in cervical cancer, anal cytology is classified as atypical squamous cells of undetermined significance (ASCUS), atypical squamous cells suspicious for HSIL (ASCH), low grade squamous intraepithelial lesion (LSIL), high-grade squamous intraepithelial lesion (HSIL) or cancer.

The introduction of population screening programs for high-grade squamous intraepithelial lesion (HSIL) is limited by little evidence that interventions alter the natural history of HPV infection and progression to anal cancer. No randomized clinical trial was conducted to validate any form of screening for anal cancer. In specific groups of patients who have an increased incidence, as men who have sex with men (MSM), the screening should be performed. In this group of patients the incidence of cancer is comparable with cervical cancer where screening is routinely performed.

The simplest screening test is the digital anal-rectal exam. The lesions would be palpable, even in the absence of clinical symptoms. This technique, although inexpensive, is not commonly used.

Anal cytology has been used since 2005, but there is still a difficulty in their interpretation. The purpose of anal cytology is to take samples of all the anal canal, including the transformation zone. Samples of cells are collected by a swab inserted into the anal canal through the dentate line, thus allowing the collection of samples of the distal rectal wall. The cytology identifies intraepithelial lesions as LSIL, HSIL, and cancer in situ. The differential diagnosis of HSIL and cancer (early invasive ASCC) is difficult. Therefore biopsy for diagnostic confirmation is necessary (Bean \& Chhieng, 2009).

A cost-effectiveness proposal is anal cytology testing every 1 to 2 years in HIV positive and men who have sex with men (MSM) HIV negative (Lam et al, 2011).

The hybrid capture test can complement cytology, with the identification of serotypes of HPV anal cancer precursors.

Taking into account the similarities with cervical cancer, was introduced a form of anal colposcopy, called high-resolution anoscopy (HRA). The HRA is indicated in those patients in whom cytology showed ASCUS, ASCH, LSIL or HSIL. Similar to colposcopy, adequate equipment and training are needed. An anoscope is introduced to approximately $2 \mathrm{~cm}$ from the anus, allowing visualization of the dentate line and the transitional zone. It is applied a solution of 3\% acetic acid. Using a gynecological standard colposcope with a light source and lens with a magnification of 20 to 30 times, the examiner tries to identify areas of dysplasia. The Lugol iodine solution is then applied revealing dysplastic areas. Vascular changes such as neovascularization, venous interruption, changes in venous caliber are also suggestive of malignant tissues. Guided biopsies are performed in these abnormal areas. A biopsy is the gold standard for identification of squamous intraepithelial lesions.

\section{Treatment of high grade squamous intraepithelial lesions (HSIL)}

There is ample evidence that HSIL is the precursor to anal cancer, although the rate of progression to cancer is unknown. 
Several treatments are recommended for the HSIL, which is a benign lesion and it takes a long time for malignant transformation.

The use of electrocautery has the advantage of being easily accessible in various surgical environments. It is less morbid than surgical excision, especially in extensive lesions. A disadvantage is that it doesn 't allows the histopathology of the lesion, and may not identify an invasive carcinoma. The recurrence with use of electrocautery is $79 \%$ in 12 months, with $100 \%$ risk at 50 months in HIV positive men. The use of high-resolution anoscopy contributes to the identification of lesions to be cleared.

A complete excision of the anal transition zone is possible, however may impair continence, being reserved for early carcinomas. Depending on the size of the lesion, the use of flaps may be necessary for the reconstruction of the skin. Surveillance anoscopy with high resolution is recommended.

In well-defined lesion with the use of Infra-Red Coagulation (IRC) can be attempted.

Topical agents may be tried. Imiquimod is an immune response modifier with potent antiviral and antitumor activity. It has been used to treat warts, basal cell carcinoma, vulvar intraepithelial neoplasia, squamous cell carcinomas of the skin, herpes and others. The application of imiquimod is safe, effective and promising in the treatment of HSIL. Topic $5 \%$ 5 -fluorouracil (5FU) may be used in combination with imiquimod.

Another topical agent cidofovir is promising. This is a 1\% gel used 5 days a week for 6 weeks for effective control of HPV. When used in intraepithelial lesions, this was proven effective in several cases (Snoek et al, 2000).

Liquid nitrogen, as well as cryotherapy, may be used.

\section{Treatment of anal cancer}

Prevention and early detection of anal cancer is of paramount importance due to the impact on survival. Patients with localized cancer of the anus have a five-year survival rate of approximately $80 \%$. Patients with metastases have a survival rate of $30 \%$.

The radio chemotherapy is the gold standard for treatment of anal cancer. Surgical treatment may be performed.

Surgical excision may be used in early carcinomas, well differentiated that did not exceed the submucosa. This type of treatment has a recurrence rate of 20 to $78 \%$ with a 5-year survival from 45 to $85 \%$. This treatment should be used in selected cases. Mobile lesions smaller than $2 \mathrm{~cm}$ are candidates for this treatment modality.

The abdomino-perineal amputation was the most widely used form of treatment in the past. Although this treatment is aggressive, the results are not encouraging. The recurrence is $27 \%$ to $50 \%$ and 5 -year survival ranges from $24 \%$ to $62 \%$ with a mortality rate of $2-6 \%$. Currently, the abdomino-perineal amputation is reserved for those patients who do not tolerate radio chemotherapy. This operation is also indicated in cases of treatment failure by radio chemotherapy.

Treatment with radio chemotherapy was initiated in 1974 by Nigro et al. The treatment involves the use of radiotherapy combined with 5 -fluorouracil ( $5 \mathrm{FU}$ ) and mitomycin $\mathrm{C}$. This 
form of treatment proposed by Nigro was used initially as a neoadjuvant regimen for abdomino-perineal amputation. After 6 weeks the patients underwent operation. Nigro noted that a number of surgical specimens showed complete pathological response, which led him to propose exclusive radio chemotherapy treatment. Other studies have been performed comparing radiotherapy alone with radio chemotherapy, showing the superiority of radio chemotherapy. Studies have also shown a better therapeutic response with the use of mitomycin $\mathrm{C}$ associated with radiotherapy and $5 \mathrm{FU}$, despite its greater toxicity.

The radio chemotherapy has complications such as dermatitis, mucositis, diarrhea, fecal incontinence, bone marrow depression, cystitis, enteritis and vascular involvement.

In cases of failure to treat with radio chemotherapy, new sessions of radiation or surgical treatment of redemption can be realized.

Brachytherapy is used as an alternative to radiotherapy with the aim of preserving adjacent organs from radiation. It is still in studies to date.

HIV patients are treated with a lower dose of radio chemotherapy than for HIV-negative patients, due to increased risks of toxicity in these patients.

Metastatic disease appears in 10 to $17 \%$ of patients treated with radio chemotherapy. The most common site of metastasis is the liver. Treatment includes chemotherapy $5 \mathrm{FU}$ combined with cisplatin, carboplatin, doxorubicin and semustine.

\section{Prognosis}

The 5-year survival for anal cancer is $80.1 \%$ for localized anal cancer, $60.7 \%$ for regional disease, and $29.4 \%$ for metastatic disease. The nodal involvement, $\mathrm{T}$ stage, and male are predictors of distant metastases, high rate of colostomy, and a worse survival with the use of radio chemotherapy. HIV-positive patients with low CD4 counts and high viral load has worse prognosis. (Abbas, 2010)

\section{HPV vaccination}

In 2006, the first U.S. FDA prophylactic vaccine against HPV was approved. The quadrivalent vaccine has proved effective in preventing infection against HPV 16, 18, 6 and 11 in healthy women. The bivalent vaccine is effective against serotypes 16 and 18 . The vaccine is recommended for women from 11 to 26 years of age before the onset of sexual activity.

As for male vaccination, is still controversial. Among the benefits related to the vaccine in males, is prevention of penile cancer, beyond the indirect benefits that women have with male vaccination. In countries like the United States, only $37 \%$ of eligible women received the vaccine in 2008. Vaccinating men might increase protection against HPV in both men and women. There is a recommendation to vaccinate men from 9 to 26 years of age.

Although the vaccine is effective in preventing cervical HPV infection, is still uncertain protection of their anal infection. Studies show the prevention of intraepithelial neoplasia type 2 and 3 . 
There are doubts about vaccination of HIV-positive, since the vaccine response in immunocompromised patients is uncertain. (Anderson, 2009)

\section{Conclusion}

Anal cancer, particularly squamous cell carcinoma is a disease whose incidence is increasing. Prevention and early diagnosis is the key to reducing mortality caused by the disease. The prevalence of HPV is currently too high and its prevention and detection constitutes a major medical challenge. HPV has an important role in the pathogenesis of anal carcinoma, especially in immunocompromised patients. Risk group subjects should take precautions. The HPV vaccine can reduce the incidence of disease in the near future and contribute significantly in reducing mortality from anal cancer.

\section{References}

Abbas A, Yang G, Fakih M. (2010). Management of anal cancer in 2010. Oncology Vol. 24, No. 4, (April 2010), pp. 364-369.

Anderson JS, Hoy J, Hillman R, et al. (2009). A randomized, placebo-controlled, doseescalation study to determine the safety, tolerability, and immunogenicity of an HPV-16 therapeutic vaccine in HIV-positive participants with oncogenic HPV infection of the anus. J Acquir Immune Defic Syndr Vol.52, No.3, (November 2009), pp.371-381.

Bean S, Chhieng DC. (2009). Anal-rectal cytology: a review. Diagnostic Cytopathology Vol.38, No.7, (2009), pp.538-546.

Chang G J, Berry J M, Jay N et al. (2002). Surgical treatment of high-grade anal squamous intraepithelial lesions. Diseases of the colon \& Rectum Vol.45, No.4, (april 2002), pp.453-458.

Chin-Hong PV, Vittinghoff E, Cranston RD et al. (2004). Age-specific prevalence of anal human papillomavirus infection in HIV-negative sexually active men who have sex with men: the EXPLORE study. The Journal of Infectious Diseases Vol.190, (December 2004), pp.2070-2076

Czoski-Murray C, Karnon J, Jones R et al. (2010). Cost effectiveness of screening high-risk HIV-positive men who have sex with men(MSM) and HIV-positive women for anal cancer. Health Technology Assessment Vol.14, No.53, (November 2010)

Darragh TM, Winkler B. (2011). Anal cancer and cervical cancer screening: key differences. Cancer Cytopathology Vol.119, (February 2011), pp.5-19.

Dietz CA, Nyberg CR. (2011). Genital, oral, and anal human papillomavirus infection in men who have sex with men. J Am Osteopath Assoc Vol 111, Supplement 2, No3, (March 2011), pp.S19-S25.

Durães LC, Sousa JB. (2010). Anal cancer and sexually transmitted diseases: What.is the correlation? Revista do Colégio Brasileiro de Cirurgia Vol.37, No.4, (2010), pp.265-268.

Fox PA. (2006). Human papillomavirus and anal intraepithelial neoplasia. Current Opinion in infectious Diseases vol. 19, (2006), pp.62-66.

Galani E, Christodoulou C. (2009). Human papilloma viruses and cancer in the post-vaccine era. European Society of Clinical Microbiology and Infectious Deseases Vol.15, (2009), pp.977-981. 
Garnock-Jones K, Giuliano A R. (2011). Quadrivalent human pipillomavirus (HPV) types 6,11,16,18 vaccine for the prevention of genital warts in males. Adis Drugs Profile Vol.71, No.5, (2011), pp.591-602.

Giuliano A R, Lee J H, Fulp W et al. (2011). Incidence and clearance of genital human papillomavirus infection in men (HIM): a cohort study. Lancet Vol. 377, (March 12, 2011), pp.932-940 .

Giuliano A R, Anic G, Nyitray A G. (2010). Epidemiology and pathology of HPV disease in males. Gynecology Oncology Vol.117, (2010), pp.s15-s19.

Gervaz P, Habnloser D, Wolff B G, et al. (2004). Molecular biology of squamous cell carcinoma of the anus: a comparison of HIV-positive and HIV-negative patients. The Society for Surgery of the Alimentary Tract Vol. 8, No. 8, (2004), pp.1024-1031.

Goldstone SE, Moshier E. (2010). Detection of oncogenic human papillomavirus impacts anal screening guidelines in men who have sex with men. Diseases of the Colon $\mathcal{E}$ Rectum Vol.53, (2010), pp.1135-1142.

Goodman M T, McDuffie K, Hernandez B Y et al. (2011). The influence of multiple human papillomavirus types on the risk of genotype-concordant incident infections of the anus and cervix: the Hawaii HPV cohort study. The Journal of Infectious Diseases Vol.203, (February 2011), pp.335-340 .

Herfs M, Hubert P, Moutschen M et al. (2011). Mucosal junctions: open doors to HPV and HIV infections? Trends in Microbiology Vol.19, No.3, (March 2011), pp.114-120.

http://www.seer.cancer.gov/statfacts/html/anus.html

Jemal A, Siegel R, Ward E, et al. (2009). Cancer statistics, 2009. CA A Cancer Journal for Clinicians Vol.59, (2009), pp.225-249.

Kreuter A, Potthoff NH, Bockmeyer T et al. (2010). Anal carcinoma in human immunodeficiency virus-positive men: results of a prospective study from Germany. British Journal of Dermatology Vol.162, (2010), pp.1269-1277.

Lam JMC, Hoch JS, Tinmouth J et al. (2011). Cost-effectiveness of screening for anal precancers in HIV-positive men. AIDS Vol.25, No.5, (2011), pp.635-642, ISSN 02699370.

Lu B, Viscidi RP, Lee JH et al. (2011). Human papillomavirus (HPV) 6,11,16, and 18 seroprevalence is associated with sexual practice and age: results from the multinational HPV infection in men study (HIM study). Cancer Epidemiology, Biomarkers \& Prevention Vol.20, (May 2011), No5, pp.990-1002.

Mavrogianni P, Alexandrakis G, Stefanaki C et al. (2011). The role of cytology and HPV typing as a screening tool in patients with intraanal warts. J Clin Gastroenterol Vol.45, No.4, (April 2011), pp.e39-e43.

McCormack P L, Joura E A. (2010). Quadrivalent human papillomavirus (types 6,11,16,18) recombinant vaccine (Gardasil). Adis Drugs Evaluation Vol.70, No.18, (2010), pp.2449-2474.

Nahas C, Lin O, Weiser M R et al. (2006). Prevalence of perianal intraepithelial neoplasia in HIV-infected patients referred for high-resolution anoscopy. Diseases of the colon $\mathcal{E}$ rectum Vol.49, (October 2006), pp.1581-1586.

Nielsen A, Munk C, Kjaer S. (2011). Trends in incidence of anal cancer and high-grade anal intraepithelial neoplasia in Denmark, 1978-2008. International Journal of Cancer (2011), pp.1-6. 
Nigro ND, Seydel HG, Considine B et al. (1983). Combined preoperative radiation and chemotherapy for squamous cell carcinoma of the anal canal. Cancer Vol. 51, (1983), pp.1826-1829.

Nigro ND, Vaitkevicius VK, Considine B Jr. (1974). Combined therapy for cancer of the anal canal: A preliminary report. Diseases of the Colon and Rectum Vol.17, (1974), pp. 354356.

Nivatvongs S. (2006). Perianal and Anal Canal Neoplasms, In: Neoplasms of the Colon, Rectum, and Anus 2nd edition, Gordon PH, Nivatvongs S, pp.305-326, Informa healthcare, ISBN-13: 978-0-8247-2959-2, New York

Ortoski RA, Kell CS. (2011). Anal cancer and screening guidelines for human papillomavirus in men. J Am Osteopath Assoc Vol 111, Supplement 2, No3, (March 2011), pp.S35S43.

Palefsky J. (2009). Human papillomavirus-related disease in people with HIV. Current Opinion in HIV and AIDS vol. 4 (2009) pp. 52-56.

Palefsky J. (2008). Human papillomavirus and anal neoplasia. Current HIV/AIDS Reports vol. 5, (2008), pp. 78-85.

Piketty C, Darragh TM, Costa MD et al. (2003). High prevalence of anal human papillomavirus infection and anal cancer precursors among HIV-infected persons in the absence of anal intercourse. Annals of Internal Medicine Vol.138, No6, (March 2003), pp.453-459.

Ramamoorthy S, Liu Y T, Loo L at al. (2010). Detection of multiple human papillomavirus genotypes in anal carcinoma. Infectious Agents and Cancer http://www.infectagentscancer.com/content/5/1/17 Vol.5, No.17, (2010), pp.1-5.

Siegel R, Ward E, Brawley O et al. (2011). Cancer statistics, 2011. CA A Cancer Journal for Clinicians Vol.61, No.4, (July/August 2011), pp212-236.

Silva I T C, Gimenez F S, Galvao R S. (2011) Performance of p16 immunocytochemistry as a marker of anal squamous intraepithelial lesions. Cancer Cytopathology (jun 2011), pp.167-176.

Sobhani I, Vuagnat A, Walker F, et al. (2001). Prevalence of high-grade dysplasia and cancer in the anal canal in human papillomavirus-infected individuals. Gastroenterology Vol. 120, no. 4, (2001), pp.857-866.

Snoeck R, Noel JC, Muller C, et al. (2000). Cidofovir, a new approach for the treatment of cervix intraepithelial neoplasia grade III. Journal Medical Virology Vol.60, (2000), pp. 205-209.

Uronis HE, Bendell JC. (2007). Anal Cancer: An Overview. The Oncologist Vol.12, (2007), pp.524-534.

Veo C A R, Saad S S, Nicolau S M et al. (2008). Study on the prevalence of human papillomavirus in the anal canal of women with cervical intraepithelial neoplasia grade III. European Journal of Obstetrics \& Gynecology andReprodutive Biology Vol. 140, (2008), pp.103-107.

Welton M L, Sharkey F E, Kahlenberg M S. (2004). The etiology and epidemiology of anal cancer. Surgical Oncology Clinics of North America Vol.13, (2004), pp.263-275.

Wilkin T, Lee J Y, Leasing S Y et al. (2010). Safety and immunogenicity of the quadrivalent human papillomavirus vaccine in HIV-!-infected men. The journal of infectious diseases Vol.202, (October 2010), pp.1246-1253. 
Wong A K, Chan R C, Aggarwal N et al. (2010). Human papillomavirus genotypes in anal antraepithelial neoplasia and anal carcinoma as detected in tissue biopsies. Modern Pathology Vol.23, (2010), pp.144-150. 


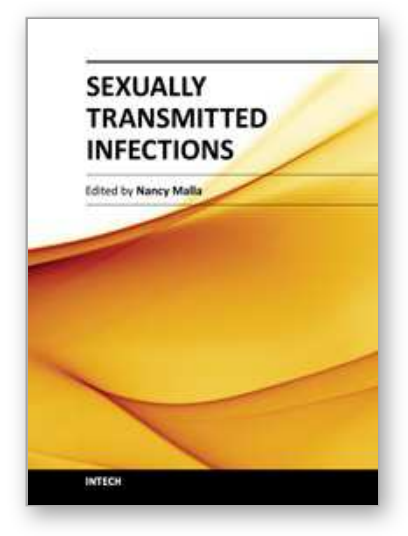

\author{
Sexually Transmitted Infections \\ Edited by Prof. Nancy Malla
}

ISBN 978-953-51-0258-8

Hard cover, 244 pages

Publisher InTech

Published online 21, March, 2012

Published in print edition March, 2012

Sexually transmitted infections (STIs) are infections that are spread primarily through person to person sexual contact. There are more than 30 different sexually transmissible bacteria, viruses and parasites. STIs lead to high morbidity and complications. This book entitled as Sexually Transmitted Infections is not a text book but provides useful information for general reference work for physicians, researchers and students interested in the subject. Each chapter is abundant in tips useful to general readers as well. It also includes the Introductory chapter providing an overview with special emphasis on syndromic approach to the management of STIs in clinical setting.

\title{
How to reference
}

In order to correctly reference this scholarly work, feel free to copy and paste the following:

João Batista de Sousa and Leonardo de Castro Durães (2012). Human Papilloma Virus and Anal Cancer, Sexually Transmitted Infections, Prof. Nancy Malla (Ed.), ISBN: 978-953-51-0258-8, InTech, Available from: http://www.intechopen.com/books/sexually-transmitted-infections/human-papilloma-virus-and-anal-cancer

\section{INTECH}

open science | open minds

\section{InTech Europe}

University Campus STeP Ri

Slavka Krautzeka 83/A

51000 Rijeka, Croatia

Phone: +385 (51) 770447

Fax: +385 (51) 686166

www.intechopen.com

\section{InTech China}

Unit 405, Office Block, Hotel Equatorial Shanghai

No.65, Yan An Road (West), Shanghai, 200040, China

中国上海市延安西路65号上海国际贵都大饭店办公楼 405 单元

Phone: +86-21-62489820

Fax: +86-21-62489821 
(C) 2012 The Author(s). Licensee IntechOpen. This is an open access article distributed under the terms of the Creative Commons Attribution 3.0 License, which permits unrestricted use, distribution, and reproduction in any medium, provided the original work is properly cited. 